\title{
Middle Palaeolithic Percussive Tools from the Last Interglacial Site Neumark-Nord 2/2 (Germany) and the Visibility of Such Tools in the Archaeological Record
}

\author{
E. Pop ${ }^{1,2}$ (D) D. Charalampopoulos ${ }^{2}$ - C. S. $\operatorname{Arps}^{3}$. \\ A. Verbaas $^{2}$ - W. Roebroeks ${ }^{2}$. \\ S. Gaudzinski-Windheuser ${ }^{1}$ - G. Langejans ${ }^{2,4}$
}

Published online: 16 April 2018

(C) The Author(s) 2018

\begin{abstract}
Despite a strong increase in the research on hominin percussive tool use, the primary focus in the study of technological behaviour still lies on flaked stone artefacts, especially for the Middle Palaeolithic. This paper aims to contribute to a more thorough understanding of the full spectrum of homi;nin technological behaviour, by presenting a systematic analysis of ground stone tools from the Last Interglacial Middle Palaeolithic site Neumark-Nord 2/2 (NN2/2) (Germany). At NN2/2, coarse gravel- and cobblesized pieces $(n=351)$ were sourced from local outcrops of glacial deposits, with a preferential selection for quartzite and sandstone. Low-power use wear analysis and the archaeological context of these finds provide evidence for the possible use of at least 58 pieces for active (hammerstones) and 5 for passive (anvils) percussive tasks, specifically lithic production and potentially bone processing. These grounds stone tools are larger and heavier than the manuports. The hammerstones were preferentially made of quartz and quartzite, while the anvils are mostly of limestone. The limited build-up of use wear on the tools is interpreted as expedient use. The presence of post-depositional
\end{abstract}

Electronic supplementary material The online version of this article (https://doi.org/10.1007/s41982-0180008-8) contains supplementary material, which is available to authorized users.

E. Pop

eduard.pop@rgzm.de

1 MONREPOS, Archaeological Research Centre and Museum for Human Behavioural Evolution, RGZM, Schloss Monrepos, 56567 Neuwied, Germany

2 Faculty of Archaeology, Leiden University, Einsteinweg 2, 2333CC Leiden, the Netherlands

3 Naturalis Biodiversity Center, Darwinweg 2, 2333CR Leiden, the Netherlands

4 Centre for Anthropological Research, University of Johannesburg, PO Box 524, Auckland

Park 2006, South Africa 
surface modifications, their relatively expedient use and their potential application on soft contact materials (e.g. nuts) resulted in a relatively low discernibility of the wear. With expediency being a key factor in Middle Palaeolithic lithic technology, we can expect comparable patterns for other similar-aged ground stone assemblages. Moreover, external factors, like geological context and raw material availability, post-depositional conditions and research focus and intensity, further contribute to the invisibility of such finds in the Middle Palaeolithic record.

Keywords Ground stone tools $\cdot$ Hammerstones $\cdot$ Anvils $\cdot$ Manuports $\cdot$ Middle Palaeolithic · Use wear analysis

\section{Introduction}

Tool use has been documented for a limited number of animals, including numerous primate species, and mostly involves percussive activities (de la Torre and Hirata 2015). Research into tool use by primates started with the pioneering work of Goodall (e.g. Goodall 1964) and currently receives much attention (Carvalho et al. 2008; Gumert and Malaivijitnond 2013; Haslam et al. 2016; Luncz et al. 2015; Roffman et al. 2012; de la Torre and Hirata 2015; Proffitt et al. 2016; Mercader et al. 2002, 2007; Whiten et al. 2009). Despite their theorised key position in the Palaeolithic technological repertoire (de Beaune 2004) and their frequent occurrence in Palaeolithic assemblages, the use of (virtually) unmodified pebbles and cobbles as tools remained understudied, particularly when compared to the more frequently occurring stone tools produced by conchoidal fracture (i.e. flaked tools) (de Beaune 1993; Dubreuil and Savage 2014). However, the strong interest in tool use by primates and the emergence of the discipline of primate archaeology have (partly) contributed to systematic research in this tool class from an archaeological perspective (Dubreuil and Savage 2014; Goren-Inbar et al. 2002; Mora and de la Torre 2005), especially for the Lower Palaeolithic (Arroyo and de la Torre 2016; Barsky et al. 2015; de la de la Torre and Mora 2010; Goren-Inbar et al. 2002, 2015; Mora and de la Torre 2005).

The traditional term for this group of artefacts is 'ground stone tools' (Adams 2002; Dubreuil and Savage 2014; Rowan and Ebeling 2008), but terms such as 'macro-lithic tools' and 'non-flint tools' are also used in the literature (Adams et al. 2009). These artefacts are produced by and/or used for flaking, pounding, abrading, pecking, grinding, drilling, etc. The tool types in these assemblages are diverse and include hammerstones, other percussive tools, abraders and grinding stones (Dubreuil and Savage 2014). For the sake of consistency with the existing literature (Adams 2002; Dubreuil et al. 2015; Rowan and Ebeling 2008), we use the term ground stone tools in this paper.

Despite the fact that ground stone tools can be informative about the evolution of percussive technology, detailed studies of assemblages of these artefacts for the Middle Palaeolithic are rare. Exceptions are studies such as Veselsky (2008) on Kabazi V in the Crimea or Thieme's (1975-1977) description of sandstone slabs with traces of use, possibly of grinding of mineral material from the early (Saalian) Middle Palaeolithic find level B3 at Reindahlen (Germany). Well-known exceptions are furthermore the (naturally or artificially) rounded limestone spheroids from Martin's excavations at La 
Quina (France) (cf. Jelinek 2013). Comparable objects were recovered from other Middle Palaeolithic sites in the southwest of France, including Combe-Grenal, La Ferrassie and Chez Pinaud, Jonzac. Roussel et al. (2009) suggest that at this last site these 'limestone balls' functioned as hammers for shaping bifacial Quina scrapers (see also Schick and Toth (1994) for a comparable interpretation of Lower Palaeolithic counterparts). Their rounded form may point to repeated use for percussive activities, suggesting that some hammerstones may have been transported. This could explain the occasionally reported absence of hammerstones at Middle Palaeolithic sites, when large scale excavations with significant amount of lithic debris are at stake (Conard and Adler 1997; Roebroeks 1988).

This paper aims to contribute to the field's knowledge of ground stone tool use by presenting a systematic, low power use wear analysis (cf. Adams et al. 2009; Dubreuil et al. 2015; Dubreuil and Savage 2014; Rots 2010; Van Gijn 2009) of an assemblage of such tools from the Last Interglacial Middle Palaeolithic site Neumark-Nord 2/2 (NN2/2) (Germany), and to fill the gap between the well-studied body of primate and earlier Palaeolithic assemblages and those produced by modern humans from the Upper Palaeolithic onwards.

The following issues will be addressed (1) what is the geological source of the coarse gravel- and cobble-sized stones of NN2/2 and how does the archaeological assemblage compare with that source in terms of raw material representation? (2) what constitutes the evidence for use of these ground stone tools and how are various types of tools (hammerstones, anvils, flaked tools) represented in the assemblage? (3) Which contact materials can be inferred from the observed wear and the archaeological context of these tools, and how does the type of wear relate to raw material type and shape? The paper will also discuss how the visibility of ground stone tools in the Middle Palaeolithic record is influenced by factors like raw material acquisition and selection, use intensity and tool function as well as (external) factors like the geological context, post-depositional conditions and research focus.

\section{Neumark-Nord 2}

NN2 is situated $170 \mathrm{~km}$ southwest of Berlin, Germany (Fig. 1) and is located in a former lignite quarry, which was in use until the early 1990s. Two small Late Pleistocene basin structures were discovered during quarrying activities. These basins were formed due to movements in the subsoil of a Tertiary brown coal diapir (Thomae 1990; Wansa et al. 2014). Neumark-Nord 1 (NN1) was archaeologically investigated from the 1980s onward, until 1995 (Mania 1990). The smaller NN2 basin (Fig. 2), which yielded the material discussed here, has been extensively excavated between 2004 and 2008 by the Landesamt für Denkmalpflege und Archäologie Sachsen-Anhalt (Germany), the Römisch-Germanisches Zentralmuseum (Germany) and Leiden University (the Netherlands), until the former quarry was intentionally inundated to create a large recreational lake (Gaudzinski-Windheuser et al. 2014; Pop 2015).

The silt loams that constitute the majority of the more or less continuously deposited basin infill (Mücher 2014; Sier et al. 2011) contained several find levels (NN2/3, NN2/ 2 , NN2/1), which yielded a total of 22,089 lithics and 125,000 faunal remains from an excavated area of $491 \mathrm{~m}^{2}$ (Gaudzinski-Windheuser et al. 2014; Pop et al. 2015). Of these, NN2/2 yielded the largest lithic assemblage $(n=18,689)$ including the coarse 


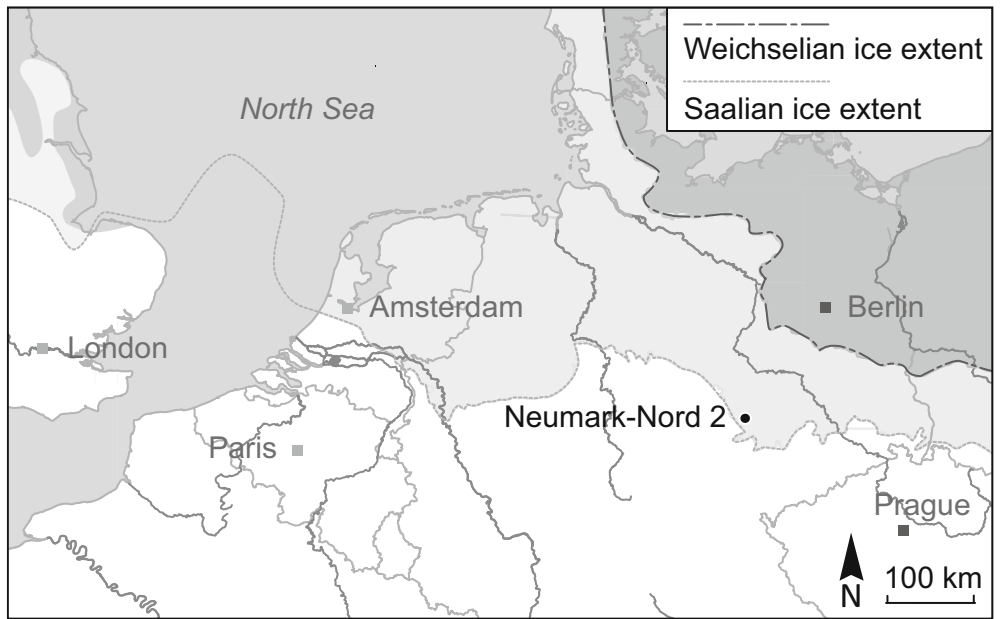

Fig. 1 Map of northwestern Europe with the location of the NN2 basin and the maximum extent of the Saalian ice. Modified from Speleers (2000)

gravel- and cobble-sized stones presented here. This level is especially find-rich in the margin area of the small lake basin and decreases in find density where it gently slopes into its deeper parts (Fig. 3). Although the levels were exposed to low energy overland flow (Mücher 2014; Sier et al. 2011), this did not cause any discernible lateral movement of the archaeological material (Pop et al. 2015; García-Moreno et al. 2016)

A large geological section near the centre of the former NN2 basin, Hauptprofil 7 (HP7), exposed its complete infill (Fig. 2). This profile was extensively sampled for various dating methods and environmental proxies (Bakels 2014; Kuijper 2014; Pop et al. 2016; Sier et al. 2011; Strahl et al. 2010). Thermoluminescence (TL) dating of heated flint artefacts from the NN2/2 level provided a weighted average TL date of 121 \pm 5 kyr B.P. (Richter and Krbetschek 2014), which is in correspondence with stratigraphic, palaeomagnetic and other studies that place the deposits in the Last Interglacial (Sier et al. 2011; Strahl et al. 2010). Sampled pollen document the complete vegetation succession of the Eemian Interglacial (Bakels 2014; Sier et al. 2011; Strahl et al. 2010). The vegetation surrounding the basin during Neanderthal presence there changed from semi-open, with its margins covered with species characteristic of grasslands and disturbed soils, to a light deciduous forest vegetation and finally, at the end of the archaeological sequence, a closed canopy Carpinus forest (Pop and Bakels 2015).

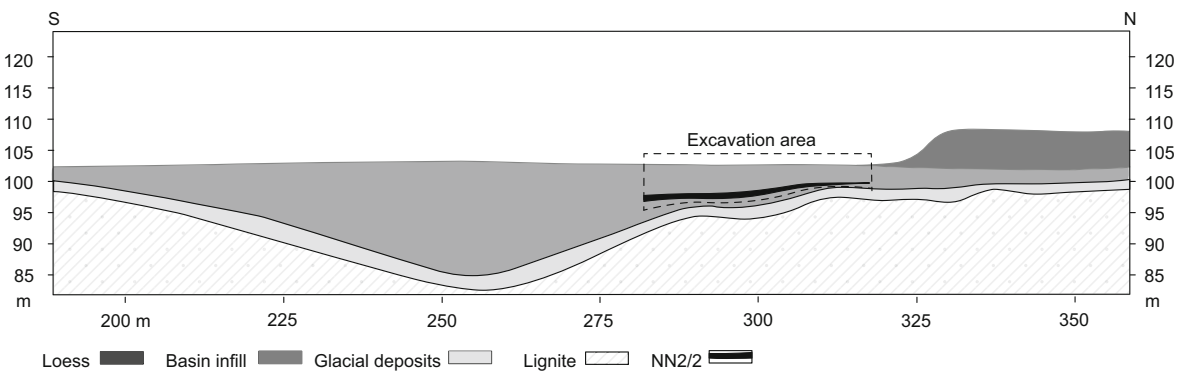

Fig. 2 Schematic cross section of the NN2 basin and excavation. Modified from Sier et al. (2011) 

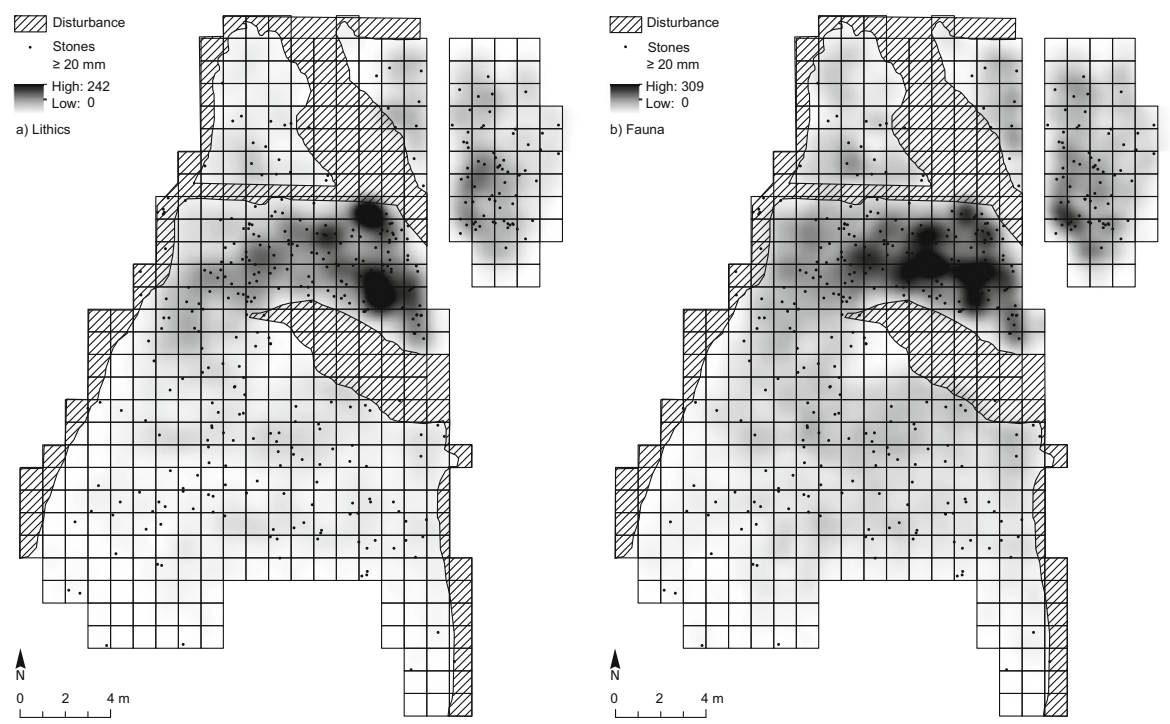

Fig. 3 Overview of the excavated area at NN2/2 and the horizontal distribution of archaeological material. a Piece plot of systematically collected, coarse gravel- and cobble-sized stones superimposed on interpolated distribution of flint artefacts. b Identical piece plot as (a) superimposed on interpolated distribution of bone finds

The faunal assemblage represents the fragmented remains of a large number $(\mathrm{MNI}=$ 175) of large ungulates, dominated by horse, bovids and red deer. There is a high incidence of cut-marks on the bones and many show traces of anthropogenic fragmentation (i.e. fresh breaks). The cut-marks and breaks demonstrate that on-site butchery activities, such as marrow extraction, took place (Kindler et al. 2014). Lithic analysis shows on-site knapping of flint nodules sourced from local glacial deposits (Pop 2014). The debitage shows large bulbs of percussion, indicating hard-hammer percussion. There is strong evidence for (repeated) fire use at this basin locality (Pop et al. 2016), consisting of charcoal concentrations in the centre of the basin that can be correlated to the distinct find levels that contain thermally altered material like heated flint and nonflint stones (see below) and heated bones. Apart from the large assemblage of flint artefacts $(15,957), 504$ gravel- to cobble-sized stones were recovered from the site, which are discussed in detail in this paper. The faunal remains, flint artefacts and coarse gravel- to cobble-sized stones $(\geq 20 \mathrm{~mm})$ show a similar horizontal and vertical distribution across the site (Fig. 3).

\section{Materials and Methods}

\section{Materials}

The assemblage of gravel- to cobble-sized stones from NN2/2 consists of 504 pieces (Table 1). Considered here are only the systematically collected, coarse gravel- to cobblesized stones equal to or larger than $20 \mathrm{~mm}(N=351$, Table 1$)$, as none of the samples taken from the assemblage of smaller-sized pieces yielded unambiguous evidence for use. 
Table 1. Composition of the coarse gravel- and cobble-sized stone assemblage from NN2/2

\begin{tabular}{llll}
\hline & $n$ & $\%$ of total & $\%^{\text {of }}$ \\
\hline Abrasive wear and fatigue & 69 & $13.7 \%$ & $81.2 \%$ \\
$\quad$ Hammerstones & 58 & $11.5 \%$ & $68.2 \%$ \\
Anvils $^{\mathrm{b}}$ & $8^{\mathrm{c}}$ & $1.6 \%$ & $9.4 \%$ \\
$\quad$ Other $^{\mathrm{d}}$ & 3 & $0.6 \%$ & $3.5 \%$ \\
Flaking & 16 & $3.2 \%$ & $18.8 \%$ \\
Flaked pieces & 11 & $2.2 \%$ & $12.9 \%$ \\
$\quad$ Flakes & 5 & $1.0 \%$ & $5.9 \%$ \\
Pieces with use wear (ground stone tools) & 85 & $16.9 \%$ & $100.0 \%$ \\
Pieces with use wear (ground stone tools) & 85 & $16.9 \%$ & - \\
No evidence for use (manuports) & 214 & $42.5 \%$ & - \\
Analysed stones (medium-light PDSM, $\geq 20 \mathrm{~mm}$ ) & 299 & $59.3 \%$ & - \\
Analysed stones (medium-light PDSM, $\geq 20 \mathrm{~mm})$ & 299 & $59.3 \%$ & - \\
Unanalysed stones & 205 & $40.7 \%$ & - \\
Heavy PDSM & 52 & $10.3 \%$ & - \\
$<20$ mm & 153 & $30.4 \%$ & - \\
Total NN2/2 stones & 504 & $100.0 \%$ & - \\
\hline
\end{tabular}

${ }^{\text {a }}$ Total pieces with usewear (ground stone tools)

${ }^{\mathrm{b}}$ Show flaking on the margins

${ }^{\mathrm{c}} \mathrm{n}=5$ after refitting

${ }^{\mathrm{d}}$ Misc. pieces showing both abrasive wear/fatigue and flaking

\section{Methods}

\section{Processing and Cleaning}

All the NN2/2 stones were cleaned on the excavation site with water and brush and subsequently labelled and individually stored in plastic bags. At the Material Culture Studies Laboratory (Leiden University), an attempt was made to clean off surface encrustations using a sonic bath, dishwashing liquid and soft brushes. In most cases, the calcite, iron-oxide and fine breccia deposits could not be removed.

\section{Raw Material Identification and Metrics}

Raw materials and grain size were identified for all systematically collected, coarse gravel- to cobble-sized stones by C.A. using a Nikon SMZ645 stereomicroscope with magnifications ranging from $\times 7$ to $\times 50$ (see Table 2 for types identified). Grain size was recorded as follows: rocks with a dominant matrix of grains over $2 \mathrm{~mm}$ were categorised as coarse grained; rocks with grains between 2 and $0.06 \mathrm{~mm}$ as medium grained; and rocks with grains smaller than $0.06 \mathrm{~mm}$ as fine grained (cf. Mathew et al. 1991; Wenthworth 1922). Compositional data on naturally occurring Saalian till deposits (Strahl et al. 2010) was used as a reference to identify potential local sources for the NN2/2 assemblage as well as raw material selection. To infer the possible degree 
Table 2 Identified rock types in the NN2/2 assemblage of analysed stones

\begin{tabular}{|c|c|c|c|c|c|}
\hline \multirow[t]{2}{*}{ Raw material } & \multicolumn{3}{|l|}{ Grain size } & \multirow[t]{2}{*}{ Total $N$} & \multirow[t]{2}{*}{ Total \% } \\
\hline & Coarse $N$ & Medium $N$ & Fine $N$ & & \\
\hline Amphibolite & 1 & 4 & 1 & 6 & 1.7 \\
\hline Diorite & 0 & 0 & 1 & 1 & 0.3 \\
\hline Flint & 0 & 0 & 8 & 8 & 2.3 \\
\hline Gabbro & 0 & 0 & 1 & 1 & 0.3 \\
\hline Gneiss(oid) & 16 & 18 & 2 & 36 & 10.3 \\
\hline Granit(oid) & 27 & 16 & 11 & 54 & 15.4 \\
\hline Iron ore & 0 & 0 & 1 & 1 & 0.3 \\
\hline Limestone & 1 & 9 & 62 & 72 & 20.5 \\
\hline Porphyry & 2 & 2 & 17 & 21 & 6.0 \\
\hline Quartz & 2 & 12 & 35 & 49 & 14.0 \\
\hline Quartzite & 24 & 23 & 50 & 97 & 27.6 \\
\hline Sandstone & 4 & 0 & 0 & 4 & 1.1 \\
\hline Unidentified & 0 & 0 & 1 & 1 & 0.3 \\
\hline Total & 77 & 84 & 187 & 351 & \\
\hline Total $\%$ & 22.1 & 24.1 & 53.7 & & 100.0 \\
\hline
\end{tabular}

of modification of the stones, the amount of cortex, or weathered rock surface, was recorded using four categories: $0-25,25-50,50-75$ and 75-100\% coverage. Furthermore, maximum dimensions were recorded using callipers, and Kern \& Sohn GmbH KBT200-2N scales were used to weigh the rocks. The massivity of the rocks was calculated by dividing the thickness with the mean of length and width. The chisquared test was used to statistically assess the differences between natural outcrops and the NN2/2 assemblage in terms of raw material composition, while Mann-Whitney $U$ (skewed distributions) or Student's $t$ tests (normal distributions) were used to statistically assess differences in metrical variables.

\section{Post-Depositional Surface Modification}

Many of the stones show modifications from their natural state, as found in primary geological contexts, including rounding and rounded striations, abrasion and pitting. These modifications can be associated with glacial transport and secondary deposition as glacial till deposits, as they cover the complete surface of the object and have a rounded, weathered appearance. This makes them easy to distinguish from more focused and fresh-appearing use wear traces. Post-depositional surface modification (PDSM) is used here to describe only (natural) modifications that occurred after archaeological deposition. Due to the fine-grained matrix within the low-energy NN2 environment, such modifications are limited to iron-oxide and calcite encrustation of the rock surface. These encrustations overlie the traces of glacial transport and use wear, as they were formed after the objects were deposited at the lake shore. The encrustations were classified as follows: 'light' when the encrustations are superficial and located in 
patches in the lower/valley parts of the rock surface and thin (e.g. Fig. 7 IV); 'medium' when the encrustations are also present on the higher parts of the surface and thicker (e.g. Fig. 7 III); and 'heavy' when crusts cover more than half of the rock on both the higher and lower parts and/or when the encrustations changed the natural shape of the rocks (e.g. Fig. 7 V). Most pieces with heavy PDSM $(n=52)$ were considered indeterminate (indet.). The remaining pieces $(n=299)$ were submitted to use wear analysis and are from here referred to as analysed stones.

\section{Use Wear}

Because a large part of the pieces showed various degrees of PDSM and cleaning with brushes was carried out on-site, a low power approach was adopted for the use wear analysis, using a stereomicroscope (Nikon SMZ645) with low magnifications $(<\times 50)$ (Dubreuil et al. 2015; Van Gijn 1989). This approach allows for the general identification of use wear areas, the interpretation of the contact material of percussion traces, and a contextual interpretation of the traces considering the morphology of the piece (Van Gijn 2014). Identification of soft contact materials requires a metallurgic microscope. However, as percussion effectively destroys previous traces, there is insufficient trace build-up (i.e. polish formation) to be studied with high magnifications. Ideally, residue analyses are carried out in parallel (Hayes et al. 2017), but PDSM, overall limited preservation of organic remains at the site, and extensive handling and cleaning of the material precluded this (cf. Langejans 2012).

Use wear attributes are interpreted using a contextual approach that compares the character and position of wear traces with experimental/ethnographic data and information about the archaeological find context. For our study, we relied on the extensive reference collection (c. 1700 experiments) of the Material Culture Studies Laboratory at Leiden University, which includes cobbles and pebbles of various raw materials with a wide range of hardnesses, and used in many different ways on large variety of contact materials. Many rock types occurring at NN2/2 are represented in the experimental reference collection, with an emphasis on quartz, quartzite, sandstone and porphyry. In addition, experimental studies show that there are general similarities in wear patterns on different stone types (Fullagar et al. 2017 and references therein), making it possible to assess the wear traces on the NN2/2 ground stone tools. Obvious limitations include the equifinality in wear attributes between different contact materials (e.g. compare Online Resource 2: 1019 and 1700) and, in the case of short usage and/or soft contact materials, a lack of observable use traces (e.g. see Online Resource 2: 1608). This means that there are different levels of inference, depending on the diagnostic weight of the traces. We used use wear analysis to interpret the motion and contact materials. The context and morphology of the ground stone tools provided further indication for their type of use.

Wear traces were studied and documented following Adams et al. (2009), who recognise four main types of wear: adhesive (residues), abrasive (striations, scratching, levelling and grain edge rounding), fatigue (crushing and fracturing of a surface) and tribochemical wear (sheen or polish) (Adams 2002; Adams et al. 2009; Adams 2014; Dubreuil et al. 2015; Dubreuil and Savage 2014). Due to the degree of PDSM, only the following features were documented to understand the contact materials: linear wear, levelling, pits/grain extraction, fractures/cracking and grain edge rounding. The 
distribution, density and orientation of these features were recorded to interpret the motion in which the artefacts were used (Adams 2002; Adams et al. 2009; Dubreuil and Savage 2014). We noted the localisation of the use wear (focused, dispersed), the number of surfaces used (one-sided, multiple-sided, opposite-sided), the degree of wear (high, medium, light) and the contact material (hard to soft).

In the used classification, a 'high' degree of wear can be observed macroscopically and, in most cases, affects the natural shape of pieces to a certain degree (e.g. Fig. 7 II, III). 'Medium' wear can also be observed macroscopically but does not affect the natural shape of the piece (e.g. Fig. 7 IV). 'Light' wear requires low power microscopy to be detected (Adams 2014, Fig. 1, X). Pitting and flaking/ fracturing are characteristic of impact/percussion damage. Hard contact materials were identified by the occurrence of deep pitting, grain extraction and flaking/ fracturing, while soft and medium contact materials by the presence of low pitting, grain edge rounding and light levelling (Adams et al. 2009; Dubreuil 2004; Dubreuil and Savage 2014).

Based on use wear localisation, inferred motion (impact/percussion), evidence for flaking, the size and shape of the tools and comparisons with the reference collection and available literature (e.g. Adams 2002; Adams et al. 2009; Dubreuil et al. 2015; Dubreuil and Savage 2014; Fullagar et al. 2015; Gilabert et al. 2012; Hamon 2008), it was possible to assign the NN2/2 pieces to one of the following object categories: hammerstones (focused pitting, high massivity, i.e. globular), anvils (dispersed pitting, pockets of focused pitting, striations, low massivity, i.e. flat), flaked pieces (intentional or accidental) and flakes (intentional or accidental). Additionally, signs of potential heating (cracking, discoloration) were noted.

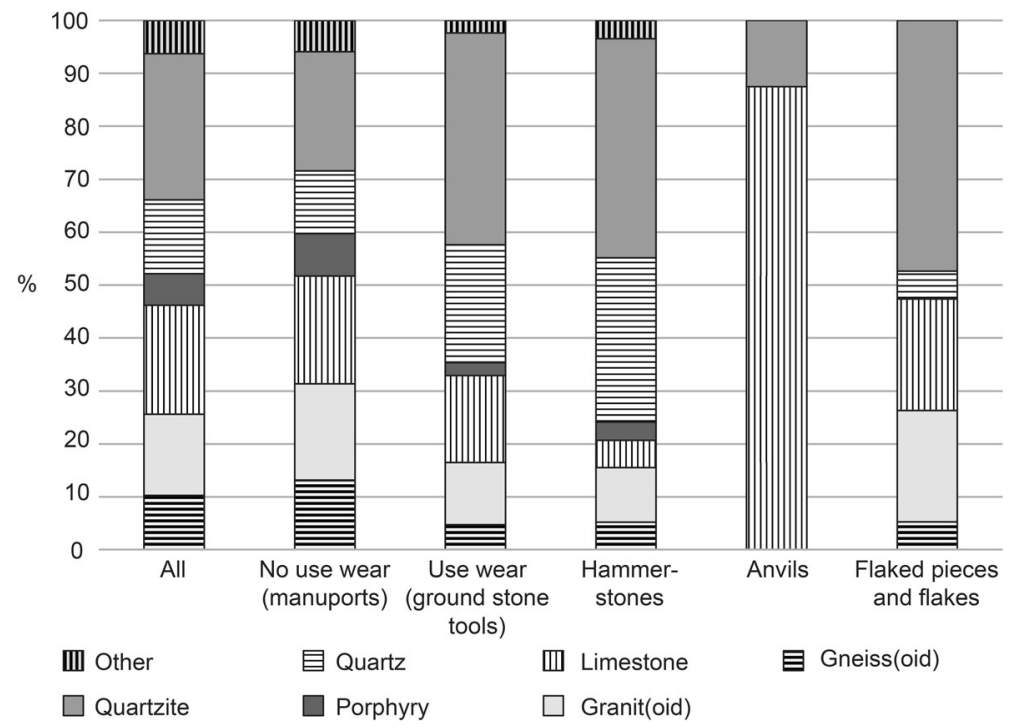

Fig. 4 Rock types in the assemblage of systematically collected, coarse gravel- to cobble-sized stones $\geq$ $20 \mathrm{~mm}$ (first column), consisting of pieces without use wear (i.e. manuports, second column) and pieces with use wear (i.e. ground stone tools, third column). The latter category has been split into three categories: hammerstones, anvils and flaked pieces (fourth to the sixth column) 


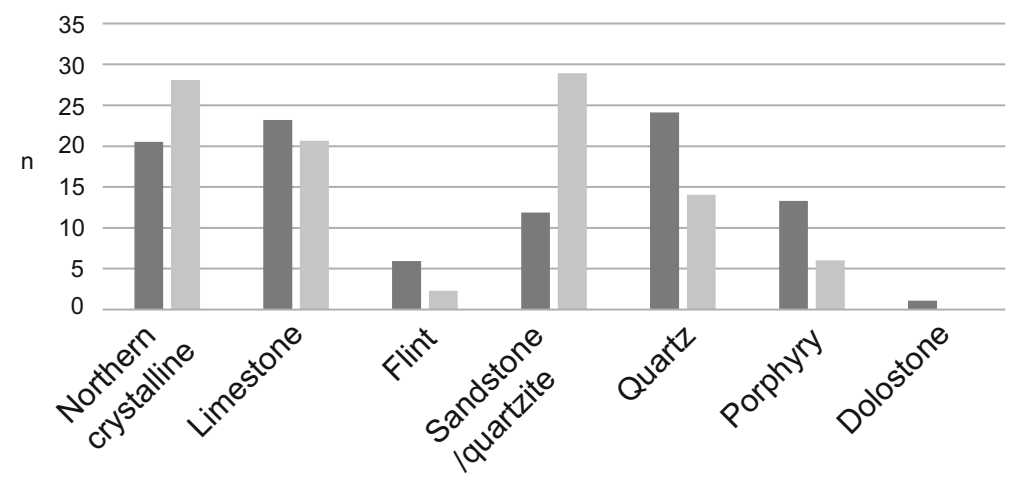

- Till sample (Strahl et al. 2010) $\quad$ NN2/2 assemblage

Fig. 5 Proportional comparison between the occurring rock types in the till sample (Strahl et al. 2010) and the NN2/2 assemblage

\section{Results}

\section{Raw Material Types and Metrics}

The assemblage of systematically collected, coarse gravel- to cobble-sized stones $(n=$ 351 , Online Resource 1 and Table 1) contains a variety of rock types, with $22 \%$ of igneous, $40 \%$ of metamorphic, $23 \%$ of sedimentary and $14 \%$ of mineral origin. The most common raw materials are quartzite $(28 \%)$, limestone $(20 \%)$, granite/granitoid (15\%), quartz (14\%) and gneiss/gneissoid (10\%) (Fig. 4, leftmost column, and Table 2). The observed rock types are all occurring in locally outcropping glacial deposits whose petrographic composition is well-known (Strahl et al. 2010, S. Wansa personal communication). The proportions are however different $\left(\chi^{2}=71.39, P<0.001\right)$ (Fig. 5). Sandstone/quartzite is overrepresented in the archaeological assemblage, while quartz and porphyry are underrepresented. The grain sizes vary between rock types but also between specimens of a particular rock type (Table 2). The NN2/2 assemblage consists mainly of fine-grained rocks (54\%); coarse- and medium-grained rocks both constitute less than a quarter of the material.

The majority of the pieces $(80 \%)$ retain their complete cortical surface, i.e. most are complete pebbles and cobbles. On $9 \%$ of the pieces, $51-75 \%$ of the cortex is present; another $9 \%$ have a natural surface coverage of $26-50 \%$; and only $1 \%$ shows less than $25 \%$ cortex.

The length of the pieces ranges from 2 to $27.6 \mathrm{~cm}$ with a positively skewed distribution around a median of $6.4 \mathrm{~cm}(\mathrm{Q} 1=3.8, \mathrm{Q} 3=7.7$; Fig. 6). Their weight ranges from ca $1 \mathrm{~g}$ up to $5 \mathrm{~kg}$, although its heavy and positively skewed distribution has a median of $72 \mathrm{~g}$ only $(\mathrm{Q} 1=27$; $\mathrm{Q} 3=110)$. The massivity ranges from 0.14 (very flat) to 0.88 (blocky or globular), with a median of $0.57(\mathrm{Q} 1=0.47$; $\mathrm{Q} 3=0.67$ ).

\section{Post-Depositional Surface Modifications}

PDSM is visible on most $(86 \%)$ of the coarse gravel- to cobble-sized stones. In some cases $(4 \%)$, it concerns post-depositional weathering of the outer surfaces. Most frequently occurring $(82 \%)$ are however encrustations of iron oxide and 
Fig. 6 Length (cm), weight (g) and massivity of the systematically collected, coarse gravel- to cobblesized stones $\geq 20 \mathrm{~mm}$ (first column), consisting of pieces without use wear (i.e. manuports, second column) and pieces with use wear (i.e. ground stone tools, third column). The latter category has been split into three categories: hammerstones, anvils and flaked pieces (fourth to the sixth column)
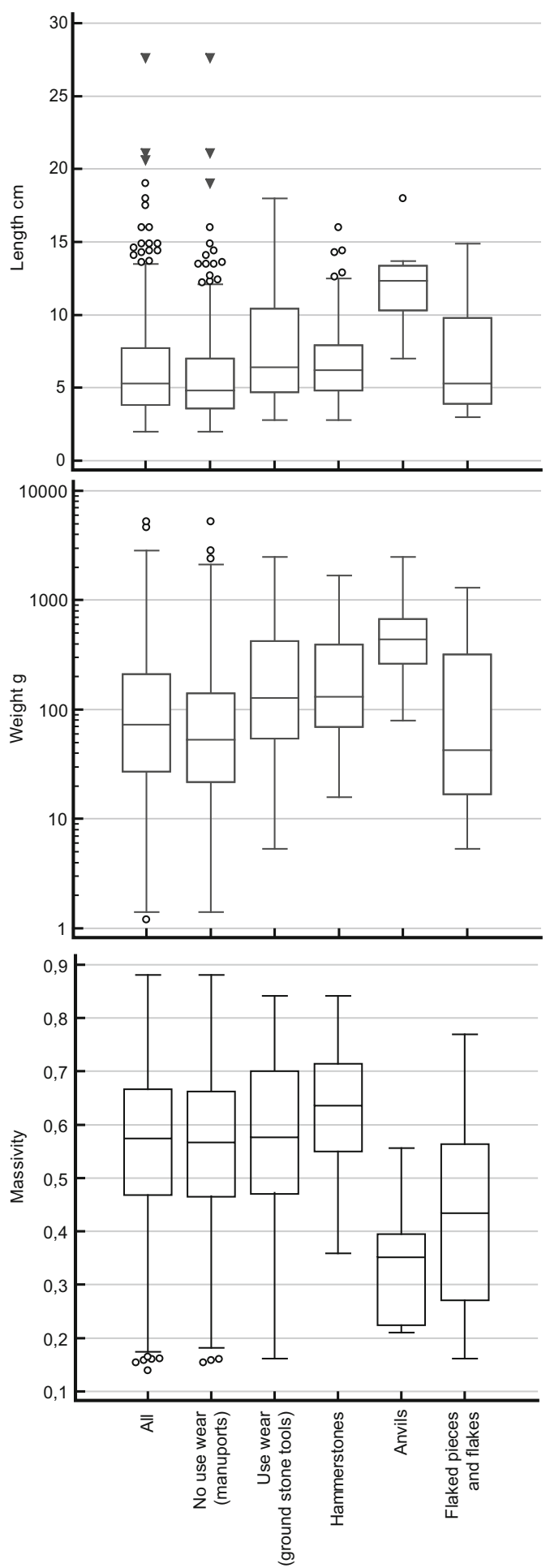


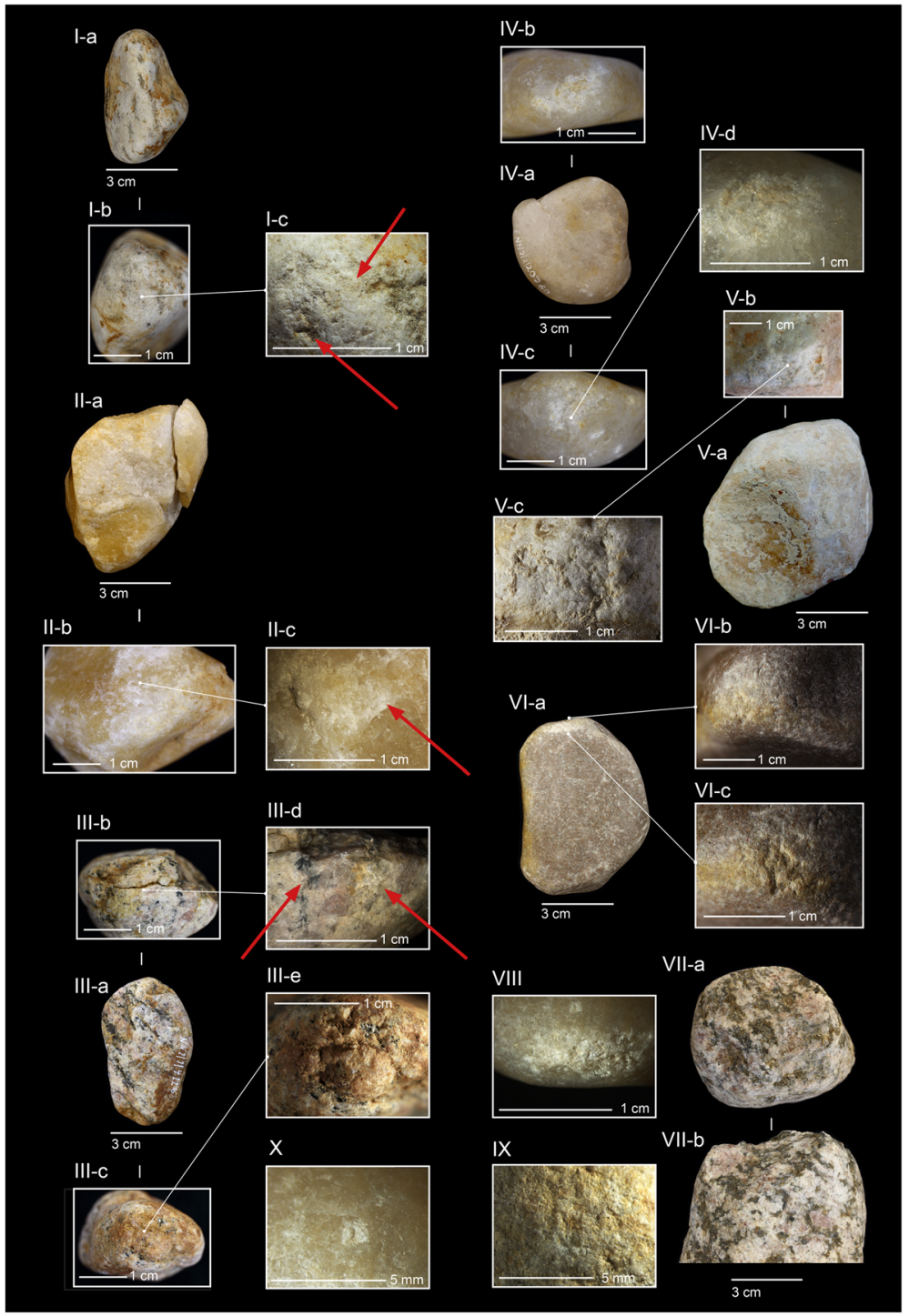

calcite that could not be removed during cleaning (see Methodology). Most pieces have a light (43\%) or medium (29\%) degree of PDSM (together $n=299$ ). On $11 \%$ of the pieces PDSM was heavy; on these pieces and those showing weathered surfaces $(4 \%)$, any use wear is obscured and they were therefore excluded from further use wear analysis.

\section{Use Wear}

Of the 299 analysed pieces, 214 pieces show no observable traces of use (Table 1). Of these, many pieces show cracking and/or discolouration; in six cases, it seems likely 
Fig. 7 Overview of the NN2/2 hammerstones, number in brackets refers to the find number. Based on the deep and/or angular pitting and fracturing, the contact material was interpreted as hard for all hammerstones. I: one-sided, medium-grained quartzite, light degree of wear and PDSM; $a=$ overview hammer, $b=$ deep pitting on protruding end, $\mathrm{c}=$ close-up of the deep and angular pitting (24461). II: one-sided with a refitted flake, medium-grained quartz, high degree of wear, light degree of PDSM; $a=$ overview of the hammer and refit, $b=$ pitting on the protruding end, $\mathrm{c}=$ close-up of deep pitting (66 and 9825). III: opposite sided, medium-grained gneiss, high degree of wear, medium degree of PDSM; $a=$ overview hammer, $b$ and $d=$ lateral view top with deep and angular pitting and extensive fracturing, $\mathrm{c}$ and $\mathrm{e}=$ lateral view bottom with deep pitting (4226). IV: multiple sided, fine-grained quartz, medium degree of wear, light degree of PDSM; $a=$ overview hammer, $b=$ deep and angular pitting top, $\mathrm{c}$ and $\mathrm{d}=$ deep and angular pitting bottom (20760). V: one-sided, fine-grained quartzite, high degree of wear and PDSM; $a=$ overview hammer, $b$ and $\mathrm{c}=$ deep pitting on top (27740). VI: one-sided, fine-grained quartzite, high degree of wear, medium degree of PDSM; $a=$ overview hammer, $b=$ deep pitting along top edge, $\mathrm{c}=$ deep pitting and fracturing along top (11531); VII: one-sided, coarse-grained granitoid, high degree of wear, light degree of PDSM; a = frontal view of extensively fractured/flaked protruding end, $b=$ lateral view of the flaking (12081). VIII: opposite sided, fine-grained quartz, medium degree of wear, light degree of PDSM; a = deep angular pitting (3633). IX: one-sided, fine-grained quartzite, medium degree of wear and PDSM (6069). X: opposite sided, fine-grained quartz, medium degree of wear, light degree of PDSM; $\mathrm{a}=$ deep pitting (3633)

that these alterations were caused by heating, but further luminescence analysis (in progress) is needed to confirm this. Most of the pieces that unambiguously show use wear $(n=85$, Table 1$)$ are complete $(47.6 \%)$. The other pieces $(n=29)$ are either broken $(8.5 \%)$ or flaked $(16.2 \%)$. Of these, 12 could be refitted into 5 refit compositions: one of quartz (Fig. 7 II), two of limestone (Fig. 8 I-II), one of quartzite (Fig. 9 I) and one of granitoid (Fig. 9 III). Of the pieces with use wear (i.e. ground stone tools; $n=85$ ), 69 show abrasive wear and fatigue (discussed in Section "Pieces with Abrasive and Fatigue Wear"). A further 16 pieces show flaking only, which cannot be attributed unambiguously to either accidental removals, flake production or shaping sequences, and are therefore separately presented in Section "Flaked Pieces and Flakes".

\section{Pieces with Abrasive and Fatigue Wear}

The pieces with abrasive and fatigue wear $(n=69,81.2 \%$, Table 1$)$ show deep and/or angular pitting/crushing, scratching/striations and flaking/fracturing (Figs. 7 and 8). The loss of single grains and crushing (fragmentation of grains) were in many cases difficult to distinguish due to the presence of post-depositional iron and calcite encrustations. In most instances, the observed pitting could be identified as impact or percussive damage ( $N=66$, Figs. 7 and 8). Compare, e.g. Fig. 7 VI with Online Resource 2: 1019. Striations are rare and only co-occur with pitting on three limestone blocks $(n=3)$. One block shows isolated striations (Fig. $8 \mathrm{I})$. The other two show multiple striations (Fig. $8 \mathrm{IV}, \mathrm{V}$ ), which are generally multidirectional, but locally parallel unidirectional (Fig. $8 \mathrm{IVd}$, Ve). The PDSM complicates detailed analysis, but the narrow and short striations appear to have a $\mathrm{V}$-shape that was probably caused by a hard and sharp implement. The long and deep striations with a bright appearance are PDSM, as they overlie post-depositional calcite deposits (e.g. Fig. 8 Va).

On 52 pieces, the wear traces are concentrated in restricted areas. On eight pieces, the wear is dispersed over their surfaces, and five have both concentrated and dispersed traces (Figs. 7 and 8). The location of the wear is generally on one side only $(N=41)$, though 22 tools were used on two or more sides. On 30 tools, the wear is highly developed (e.g. Fig. 7 II, III, V and Fig. 8 V); however, none were shaped by the 


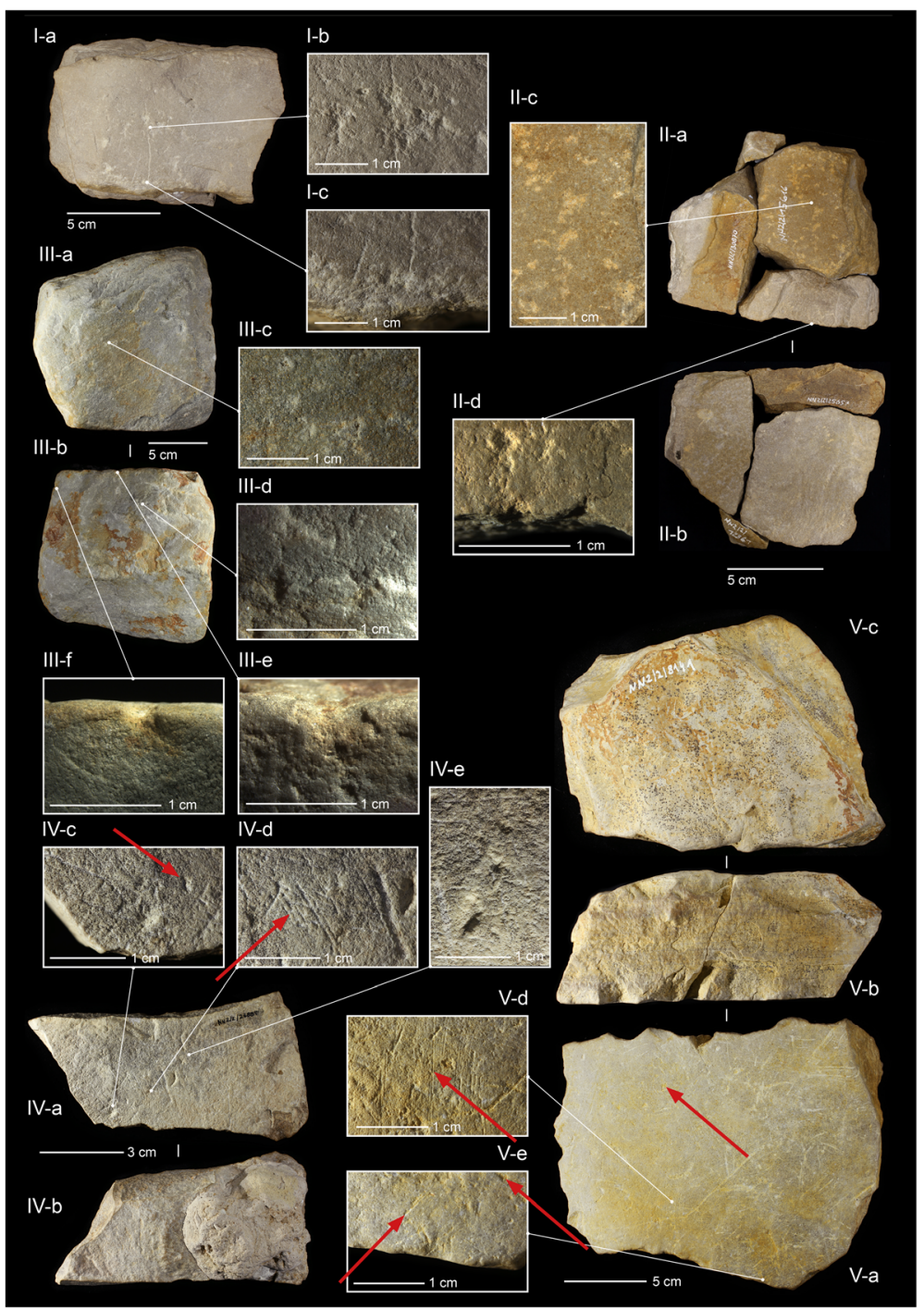

Fig. 8 Overview of the NN2/2 anvils, number in brackets is the find number. I: flaked and battered refit group, fine-grained limestone, medium degree of wear and PDSM, hard contact material; $a=$ front with use wear, $\mathrm{b}=$ deep angular pitting, $\mathrm{c}=$ deep pitting and battering damage on side and striations (1943 and 25656). II: anvil refit group, fine-grained limestone, medium degree of wear and PDSM, hard contact material; $\mathrm{a}=$ front with use wear, $\mathrm{b}=$ back of the anvil with no use wear, $\mathrm{c}=$ deep angular pitting, $\mathrm{d}=$ deep pitting and flake removals along edge (15616, 30870 and 25657); III double sided anvil, finegrained quartzite, medium degree of wear, high degree of PDSM, medium hard (in c) and unidentified contact materials; $a=$ front object with micro wear, $b=$ back of the object with micro wear, $\mathrm{c}=$ deep and shallow/rounded pitting, $\mathrm{d}=$ deep pitting, $\mathrm{e}=$ flake removal, $\mathrm{f}=$ flake removal (25867); IV flaked anvil, fine-grained limestone, light degree of wear and heavy degree of PDSM, unidentified contact material; $\mathrm{a}=$ front with use wear, $\mathrm{b}=$ back without use wear, $\mathrm{c}=$ deep pitting, striations and flake removals along the edge; $\mathrm{d}=$ parallel striations, e = deep pitting (26884); V flaked anvil, fine-grained limestone, high degree of wear, medium degree of PDSM, unidentified contact material; $\mathrm{a}=$ front with use wear, $\mathrm{b}=$ lateral view with flake removals, $\mathrm{c}=$ back without use wear, $\mathrm{d}=$ parallel striations, $\mathrm{e}=$ striations and pitting $(8141)$ 


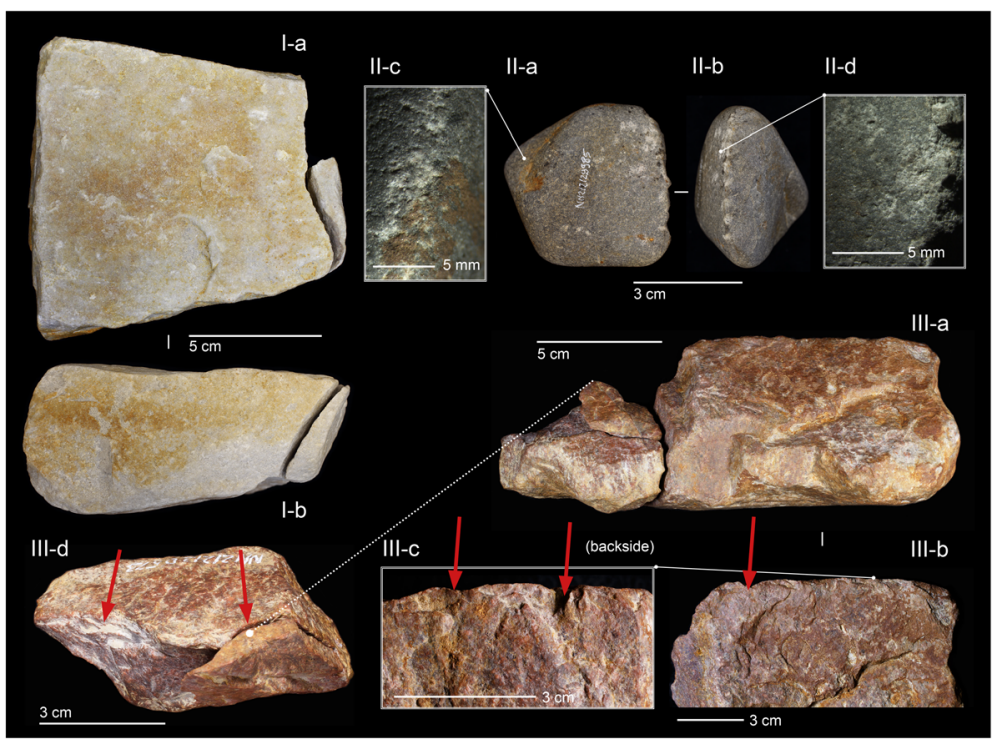

Fig. 9 Examples of NN2/2 flaked pieces and a tool, number in brackets is the artefact number. I: flaked block with refitted flake, medium-grained quartzite, light degree of PDSM (12903 and 18213). II: tool with percussion marks, fine-grained quartzite, light degree of PDSM (29985). III: two flaked pieces and a flake that form a refit group, small piece on the left-hand shows damage from repeated hammering, the large piece on the right-hand has small bifacial removals, fine-grained granitoid, light degree of PDSM (28513, 258975 and 10492)

modifications, and generally the wear is well-developed in one of two locations. On 19 tools, the wear was moderate (e.g. Fig. 7 IV, VIII and Fig. 8 I, II), and on 16 lightly developed (e.g. Fig. 7 I and Fig. 8 IV). Due to the coarse grains of the rock type or PDSM, the wear intensity could not be determined in three cases. The contact material is in most cases hard $(N=62)$ and in one case medium hard, while for the remaining tools, the contact material could not be determined. Compare, e.g. the deep pitting with angular edges and flaking of the NN2/2 stones in Fig. 7 with similar damage on the experimental hammers in Online Resource 2: 528, 1019, 1222 and 1292. These experimental hammers were used on hard contact materials. Note that softer materials leave no traces (Online Resource 2: 1608) or shallow rounded pitting (Online Resource 2: 1284). Based on the type (pitting/crushing) and localisation (focused) of wear traces, the majority of the tools $(68.2 \%)$ could be classified as active percussive tools, i.e. hammerstones $(N=58$, Fig. 7 and Table 3$)$, of which most are one-sided $(N=36)$ and the

Table 3 Identified percussive tool types, their frequency and key attributes

\begin{tabular}{lll}
\hline Tool type & Hammerstone & Anvil \\
\hline Frequency $N(\%$ of ground stone tools $)$ & $58(68 \%)$ & $8(9 \%)$ \\
Type of wear & Pitting/crushing & Pitting/striations \\
Location of wear & Focused & Dispersed \\
Contact material & Hard & Medium/hard \\
Flaking & Accidental & Shaping/accidental
\end{tabular}


rest multiple-sided $(n=13)$ or dispersed $(n=1)$. The contact material of 55 hammers was interpreted as hard, for three the contact material remains unidentified. Observe the similarities between the focussed pitting of the NN2/2 hammerstones in Fig. 7 and the experimental hammers in Online Resource 2. One piece of quartz showed a flake negative on which a quartz flake could be refitted, which is most likely an accidental removal during percussion.

Eight pieces ( $n=5$ after refitting) that show both use wear and flaking (Fig. 8) show mostly dispersed pitting and striations caused by contact with medium $(n=1$, Fig. 8 IIIc) to hard ( $n=2$, Fig. 8 I and II) contact materials (compare the deep and well-defined pitting on the NN2/2 tools in Fig. 8 with similar damage on experimental anvils used on medium hard and hard contact materials in Online Resource 2: 1961 and 1021; note that damage from softer contact materials is shallow and rounded, as in, e.g. Online Resource 2: 1285). The striations might be confused with glacial damage, but their presence on one side without the clear weathering as visible on the opposite side seems to exclude this possibility. These pieces can be classified as passive (mostly percussive) tools, i.e. anvils (Fig. 8 and Table 3). One anvil was used on two sides (Fig. 8 III), and another refitted anvil was used on two sides (Fig. 8 I). Extensive striations are only present on two anvils, which in some areas show directionality (Fig. 8 IV and V). All five anvils have battered lateral sides and show flake removals with step terminations (Fig. 8 I-III).

\section{Flaked Pieces and Flakes}

Of the flaked pieces and flakes $(n=16,18.8 \%$, Table 1), five are flakes that either fit to hammerstones $(n=1)$ or flaked pieces (i.e. cores, $n=4)$. The other 11 pieces are flaked pieces, which show relatively small removals often terminating in step fractures (Fig. 9 I, III). One of the pieces is tablet-shaped and shows removals along its margins, possibly as preparation for use as an anvil (Fig. 9 I). Another flaked piece shows clear signs of percussion damage, with small flakes bifacially removed from a relatively sharp edge (Fig. 9 III-b, c), but it was not possible to interpret the damage in terms of use. Other flaked pieces could be related to hammerstone use as they show removals typical for percussion damage, but lack clear use wear.

\section{Material Characteristics and Use}

Proportional differences in raw material types between the pieces without use wear and the pieces with use wear (i.e. ground stone tools) are significant $(\chi=22.63, P<0.001)$ and show a proportional increase in quartzite (23 to $40 \%)$ and quartz (12 to $22 \%$ ) for the pieces with use wear (Fig. 4). The difference is even more significant for the hammerstones $(\chi=29.67, P<0.0001)$, represented by a further increase of quartz/ quartzites (63 to $72 \%$ ). Clear differences can be seen between the groups within the category of ground stone tools: the anvils are the most diverging with predominantly limestone (Fig. 4); the category flaked pieces is not significantly different from the hammerstones $(\chi=10.51,0.05>P>0.01)$ (Fig. 4).

A comparison of the metrical characteristics (length, weight) is shown in Fig. 6. For length and weight, the ground stone tools are significantly larger and heavier than the pieces without use wear $(u=6750.50, z=4.470, P<0.0001$ and $u=6675.00, z=$ 4.573, $P<0.0001)$, while retaining the same massivity $(t=0.594, P=0.5532)$. The same is true in terms of size and weight for the largest group of ground stone tools, the 
hammerstones $(u=4708.50, z=3.682, P=0.0002$ and $u=4125.50, z=4686$, $P<0.0001)$, although these tend to be more globular in shape $(t=3.882, P=0.0001)$. Among the categories of ground stone tools, the anvils are twice the size, four times the weight of the hammerstones $(u=59.50, z=3.389, P=0.0007$ and $u=122.00, z=2.161$, $P=0.0307)$ and significantly flatter $(t=7.262, P<0.0001)$, while the hammerstones are in turn double the size and about triple the weight of the other flaked pieces $(u=479.00$, $z=0.851, P=0.3949$ and $u=363.00, z=2.221, P=0.0263)$. These differences in size and shape of the use wear pieces are of course not surprising as they play a role in determining the type of tool use (see Methods).

\section{Discussion}

\section{Neumark-Nord 2}

\section{Raw Material Acquisition, Selection and Transport}

The coarse gravel- and cobble-sized stones described in this paper do not naturally occur in the fine-grained silt loams (5\% clay, $70 \%$ silt, $25 \%$ fine sand) that constitute the basin infill (Mania and Thomae 2013), and deposition by means of high-energy transport can be excluded (Mücher 2014; Pop et al. 2015). Furthermore, their overlapping distribution with unambiguously anthropogenic flint artefacts and modified faunal remains (Fig. 3) indicates that these stones are not a natural component of these deposits. Due to their allochthonous nature, they can a priori be considered 'manuports', i.e. stones transported by hominin agency (Leakey 1966; Mora and de la Torre 2005). It is likely that the transported assemblage originates from locally occurring glacial deposits which can be attributed to the Drenthe stadial of the Saalian glacial (Strahl et al. 2010; Wansa and Radzinski 2004), due to the observed similarities in occurring rock types (Fig. 5). These glacial deposits, underlying the NN2 basin infill by $>1 \mathrm{~m}$ at the main find area, come closer to the find level at the outer rim, possibly outcropping at that time beyond or just within the excavation area (Hesse and Kindler 2014: Fig. 19). Despite the similarities in rock types, there are some discrepancies in their proportions (Fig. 5), which may be caused by differences in the size classes studied $(>20 \mathrm{~mm}$ for the NN2/2 material and $6.3-20 \mathrm{~mm}$ for the sampled glacial deposits). Alternatively, it may point to raw material selection before anthropogenic transport.

\section{Use Intensity of Percussive Tools}

Of the material transported to the main NN2/2 activity area that is not heavily affected by PDSM $(n=299), 214$ pieces do not provide conclusive evidence for being modified and/or being used. Apart from not being modified or used, pieces may have ended up in this category due to (a) medium to light PDSM which obscures use wear; (b) lowintensity use (see below) that remains undetected despite the absence of PDSM (i.e. soft contact materials and few repetitions/short duration and/or little force applied); and (c) raw material properties (e.g. coarse-grained rocks) that obscure use wear. From a behavioural point of view, the manuports may have been transported for future use, or they were used for activities that left little or no traces visible with our low power 
approach, like breaking fresh bone, for which the NN2/2 faunal record provides clear evidence (see below).

A total of 85 pieces show unambiguous use wear. In general, the percussive tools $(n=66)$ only show light to moderately developed use wear. Often, most of the cortical surface remains, suggesting that, in the case of heavy duty use (e.g. knapping flint), they were used for relatively short periods. This pattern of low curation is reflected in the flint industry of mostly (small) flakes with little retouch (apart from occasional notches and denticulates) and/ or little evidence for resharpening, which can be explained as an opportunistic and ad hoc use of lithic resources (Pop 2014). Rather than a high degree of technological investment, coarse gravel- and cobble-sized stones as well as flakes, produced in quantity without predefined shapes in mind, seem to have been provisioned and picked up for use when necessary (cf. Turq et al. 2013): a resource strategy facilitated by the proximity of lithic sources.

\section{Percussive Tool Function}

Stones of relatively globular shape showing concentrated pitting/crushing can be interpreted as active percussive tools, i.e. hammerstones $(n=58)$. The wear indicates they were used on hard contact materials, such as stone and dry bone (Verbaas and Van Gijn 2008). An abundance of flint artefacts $(n=15,957)$ showing a similar distribution as the hammerstones (Fig. 3a) has been recovered from the site, including cores and flakes, and the large bulbs of percussion observed on the latter can be associated with the use of stone hammers for knapping flint (Pop 2014). Another hard contact material could have been stone anvils that were accidentally hit, which is discussed in more detail in the next section. Dry bone can be excluded as contact material; although a significant part (ca. 25\%) of the faunal remains from NN2/2 show dry breaks, including (refitted) flakes, they do not show any signs of dynamic and/or static load responsible for removal and thus most likely reflect weathering through repeated wetting and drying (Kindler et al. 2014). It is on the other hand possible that fresh bone was a contact material that did not leave diagnostic wear on the hammers. Most faunal remains show spiral fractures with flat surfaces indicative of marrow extraction, as well as scars and negatives of internal flake removal by hammerstone impact (Kindler et al. 2014; L. Kindler personal communication). Given the large number of faunal remains showing these characteristic breaks, the high number of animals represented (with an MNI of 175 large ungulates) and the overlapping distribution of the faunal remains and hammerstones (Fig. 3a, b), it is very likely that the latter have been used on both flint and faunal remains.

Relatively large and flat stones showing dispersed pitting, flaking/battering of the margins and striations can be interpreted as passive percussive tools, i.e. anvils $(n=8)$. The pitting on the anvils is related to percussion damage caused by medium $(n=1$, Fig. 8 IIIc) and hard ( $n=2$, Fig. 8 I and II) materials (remaining are unidentified); the former could indicate contact with fresh bone, while the latter could indicate contact with stone, like with hammerstones during nut or bone cracking, with flint/ hammerstones during bipolar knapping, or from contact with dry bone. As shown experimentally, damage from nut cracking and pounding is limited and mostly consists of accidental impact marks through hammerstone contact, while the nuts absorb most of the energy (Arroyo and de la Torre 2016; de la Torre et al. 2013). Hazel shrubs were abundant in the local environment (Bakels 2014; Pop and Bakels 2015; Strahl et al. 2010) and a few charred hazelnut remains have been found at the NN $2 / 2$ site 
(Kuijper 2014), similar to the evidence from other Eemian sites (Hérisson et al. 2015; Thieme et al. 1985; e.g. Toepfer 1958). As the absence of more hazelnut remains (which do not require roasting before consumption) can be attributed to the poor preservation of uncharred botanical remains (Kuijper 2014; Pop et al. 2015), nut cracking cannot be excluded as a potential use for the anvils. Pounding of deshelled nuts appears unlikely as we did not observe the related damage (e.g. Online Resource 2: 1223). The anvils might have been used for bipolar knapping, but given the low intensity use wear on them (e.g. de la Torre et al. 2013; Jones 1994 and compare the damage in Online Resource 2: 1021 with 1961) and the lack of cores and debitage showing features characteristic of the use of this technique (Pop 2014), this is unlikely. Contact with dry bone is also implausible given the type of damage observed on the bones (see above). Apart from major (accidental) impact which caused fragmentation of the anvils, most of the anvil pieces show controlled, and occasionally extensive, flaking at the margins (Fig. 8), possibly indicating purposeful shaping of the object. The (step) flaked and battered anvil edges of two pieces (Fig. 8 I, III) may result from breaking bones, by placing the latter against the side of the anvil and striking it with a hard hammer (de la Torre et al. 2013: Fig. 5; Arroyo and de la Torre 2016) or alternatively smashing the bones directly against the anvil (Blasco et al. 2014). Like with nut cracking, missed blows during bone breakage may have caused pitting and/or anvil fragmentation as well (ibid.). As discussed above, the large assemblage of freshly fragmented faunal remains supports a bone processing scenario at the site (Kindler et al. 2014). On one anvil-like piece, striations with v-shaped cross section, of variable length, depth and orientation, cover most of one flat surface and are locally parallel (Fig. $8 \mathrm{~V}$ ). The latter type of striations are most likely incisions made with a sharp and hard tool, possibly using a cutting motion. One piece showing shared characteristics with the other anvils (raw material, shape, weight) show flaked sides but lacks use wear and may therefore represent an anvil blank. On the whole, the pitting and associated fracturing on the anvils is most likely caused by incidental contact with a hard hammer and possibly by breaking fresh bones. The flaking on the lateral sides of the anvils might also be related to bone breaking.

It cannot be excluded that a large part of the flaked pieces and flakes $(n=19)$ are associated with percussive tool use, i.e. representing respectively hammerstones with accidental removals on their protruding ends and accidental removals from such pieces or removals from anvils - rather than being part of a dedicated core-and-flake industry (e.g. Mora and de la Torre 2005). This notion is supported by the small size of the knapped non-flint assemblage, the unsuitability of this raw material for knapping compared to the similarly-sourced 15,957 flint artefacts and the lack of longer reduction sequences for this material category. Nevertheless, clear use wear is lacking on most of these knapped pieces and associated flakes. This may suggest that these pieces were quickly discarded and considered unsuitable as hammerstones, as they do not allow energy to be transmitted uniformly into the flint and not used as so-called active "hammerstones with fracture angles" (Mora and de la Torre 2005, p. 181). Other flakes likely represent either accidental removals from anvils (e.g. when using the battering technique) or perhaps intentional shaping of anvils (see Fig. 8 IV, V).

The cobble- and pebble-sized stones found at NN2/2 clearly played a key role in both technological and subsistence behaviour at the site. The interpreted hammerstones were probably used to produce flint artefacts for butchering large herbivores $(n>175)$, and the anvils may also have been used to process bones. Although likely, there is no 
evidence for nut cracking of nuts from nearby hazel stands. Because of the high fragmentation rate of the bones and the presence of potentially heated stones, studies are being undertaken to identify higher degrees of resource intensification in the form of grease rendering (i.e. boiling bones with cooking stones, see, e.g. Nakazawa et al. 2009). It cannot be ruled out that particular tools were used for more than one activity, given the overlapping distributions of flint artefacts, smashed bones, cobble- to pebblesized rocks and percussive tools in particular.

\section{Functional Selection Criteria}

The difference in the proportions of rock types and differences in size/weight between the modified/used and unmodified/unused pieces suggests that further selection took place after transport (Figs. 4 and 6). It can however not be excluded that stones without observable traces were used for light duty/short tasks.

Clear differences in characteristics can be observed between the percussive tools: whereas the hammerstones are predominantly natural, strongly rounded crystalline rocks (especially quartzite and quartz), the anvils are mostly block-like pieces of limestone (and one quartzite) with flat surfaces following natural fracture planes in the stone. For the hammerstones, the choice of raw material is most likely related to its hardness of 7 Mohs and its fine grain size, as with coarse-grained hammerstones aggregates break off during impact and part of the force may be absorbed into the hammer. For the anvils, the flat fracturing surfaces of the selected raw materials may have played a key role: they take up a stable position on the ground and the upper side makes a good working platform for various activities.

\section{The Invisibility of Ground Stone Tools in the MP Record}

The intensity of use and the rate of discard of ground stone tools depended to a significant degree on the ease of access for hominins to sediments containing gravelto cobble-sized rocks. In the case of NN2, glacial deposits were used as a source for such stones, but beaches, rivers and primary deposits would have served as well. Levels of mobility and raw material use strategies also affect the visibility of ground stone tools in the archaeological record. Curation behaviour in particular may be linked to a mobile lifestyle and/or shortage of resources. It improves the recognisability of these tools but leads to a higher numerical underrepresentation in a record that is already strongly dominated by flint artefacts and faunal remains. Expedient use, as reflected in the NN2/2 percussive and flint tools, potentially indicates lower mobility and/or a higher availability of resources and results in low intensity use wear which is more difficult to recognise (Dubreuil and Savage 2014; Van Gijn 2014). Although a certain degree of curation can be observed in the Middle Palaeolithic record, in particular in flaked stone technology (e.g. handaxes), expedient tool use still played a dominant role; only with the Upper Palaeolithic the use of curation becomes a key component in technological behaviour (Vaquero and Romagnoli 2017). This contributes significantly to the recognition of and research focus on such tools from this period and makes it easier to interpret the function (de Beaune 2004). Percussive tools of other materials, like bone, antler and wood, were also used at NN2/2 (Lutz Kindler, personal communication) and at other Palaeolithic sites, which may be related to task-specific material 
properties or a scarcity of gravel- to pebble-sized rocks. Apart from potential expediency of ground stone tools and the use of non-lithic materials, the invisibility of the former may be further enhanced by their application on soft contact materials. While flint knapping leaves clear traces on percussive tools, contact with meat and nuts leave few to no visible traces, decreasing their chances of recovery and being recognised as tools (Dubreuil and Savage 2014; Van Gijn 2014). Another factor that may play a role is exposure to fire. As observed in the NN2/2 assemblage, some pieces show evidence for being heated, which, when done repeatedly or for longer periods of time, can easily obliterate any sign of use through fragmentation, spalling and exfoliation (Deal 2012).

After deposition and during burial of the ground stone tools, taphonomical processes can further influence their spatial and physical integrity, affecting chances of recovery and identification. In order to be discovered in the first place, their association with unambiguous flint artefacts and faunal remains is critical. Processes like winnowing are, however, able to laterally sort the lighter elements like bone fragments and flint artefacts from these heavier finds. But even when the lighter archaeological elements are without doubt in situ and co-occurring with gravel- and cobble-sized rocks, natural explanations for their co-occurrence (i.e. gravel- and pebble-sized rocks already present before deposition of archaeological remains) should be excluded before hominin agency is inferred (i.e. manuports). In this way, reappraisals of local geological conditions have led to the dismissal of several assumed manuport assemblages (Leakey 1966; Mora and de la Torre 2005). PDSM can have a detrimental effect on the preservation and/or visibility of use wear. In the case of NN2/2, difficult-to-remove encrustations of calcite and iron covered potential use traces. Depending on the geological context of the finds, chemical and mechanical weathering can have a more significant and permanent effect on such finds.

The last group of factors that determine the visibility of ground stone tools in the archaeological record include excavation strategies, find processing and research priorities. In many cases, gravel- to pebble-sized rocks are not (systematically) collected because of the aforementioned difficulty to distinguish human transported and used material from natural occurrences. When they are collected, the decision to clean them in the field can be both instrumental in revealing traces but can also have a destructive effect on the residues and the wear, specifically for the high power approach. When encrustations are not removed or if they cannot be removed, as is the case for some of the NN2/2 pieces, often these pieces cannot be analysed for use wear at all. Finally, research priorities play an important role in the visibility of this tool type: the focus mainly lies on curated technologies due to their theorised significance as cultural markers, while expedient ones have been mostly ignored (Vaquero and Romagnoli 2017).

\section{Conclusion}

The analysis of the NN2/2 assemblage of coarse gravel- and cobble-sized pieces shows that they were sourced from a local till deposit, with an emphasis on quartzite and sandstone. Analysis of these stones shows that 63 of them were part of a percussive toolkit that consisted of both passive (anvils) and active (hammerstones) tools. The wear suggests that the hammerstones, preferentially of quartz and quartzite, were specifically used on hard materials. The damage on the quartzite and limestone anvils 
most likely results from incidental contact with hammerstones and possibly from fresh bone breaking, activities also reflected in other archaeological finds from the site. The archaeological context does not preclude soft contact materials for these stones as well, e.g. nut processing. The expediency and low levels of use intensity of lithic technology that characterise both the lithic technology of NN2/2 and of the Middle Paleolithic in general can be expected to negatively affect the visibility of ground stone tools in the archaeological record of this period. This in turn limits systematic recovery and analysis, and ground stone tools may therefore not receive the same level of recognition and analysis as curated tools, especially where an archaeological site's sedimentary matrix contains larger numbers of naturally occurring stones - unlike the fine-grained infill of the NN2 basin.

The study of coarse gravel- and cobble-sized stones from NN2/2 and their archaeological context provide an insight into the use of percussive tools at a Middle Palaeolithic site, providing a much broader perspective on Neandertal technology than studies based on the knapped tools alone. This research underlines the key position of percussive tools at the base of the technological repertoire, being instrumental in producing sharp-edged flint artefacts which may in turn have produced artefact categories made from other (perishable) materials, like, e.g. the wooden hunting spear from Lehringen. Whether directly used or through subsidiary technologies, ground stone tools are essential elements in the Neandertal toolkit and play a critical role in their subsistence behaviour.

Acknowledgements We would like to thank Annelou van Gijn and the Material Culture Studies Laboratory (Leiden University) for providing the infrastructure for our analysis. Further thanks go out to Dr. Stefan Wansa (Landesamt für Geologie und Bergwesen Sachsen-Anhalt) for providing detailed data on the composition of the till at NN2. Richard Devey (University of Johannesburg) is thanked for his help and advice with the statistics. We are also indebted to Christina Tsoraki and Andrew Sorensen for comments on earlier drafts. Geeske Langejans's research is sponsored by the Netherlands Organisation for Scientific Research (NWO) with a Veni grant (the Netherlands).

\section{Compliance with Ethical Standards}

Conflict of interest On behalf of all authors, the corresponding author states that there is no conflict of interest.

Open Access This article is distributed under the terms of the Creative Commons Attribution 4.0 International License (http://creativecommons.org/licenses/by/4.0/), which permits unrestricted use, distribution, and reproduction in any medium, provided you give appropriate credit to the original author(s) and the source, provide a link to the Creative Commons license, and indicate if changes were made.

\section{References}

Adams, J. (2002). Ground stone analysis: a technological approach. University of Utah Press.

Adams, J. (2014). Ground stone use-wear analysis: a review of terminology and experimental methods. Journal of Archaeological Science, 48, 129-138. https://doi.org/10.1016/j.jas.2013.01.030.

Adams, J., Delgado, S., Dubreuil, L., Hamon, C., Plisson, H., \& Risch, R. (2009). Functional analysis of macro-lithic artefacts. Functional analysis of macro-lithic artefacts 2006, Portugal. 
Arroyo, A., \& de la Torre, I. (2016). Assessing the function of pounding tools in the Early Stone Age: a microscopic approach to the analysis of percussive artefacts from Beds I and II, Olduvai Gorge (Tanzania). Journal of Archaeological Science, 74, 23-34. https://doi.org/10.1016/j.jas.2016.08.003.

Bakels, C. (2014). A reconstruction of the vegetation in and around the Neumark-Nord 2 basin, based on a pollen diagram from the key section HP7 supplemented by section HP10. In S. Gaudzinski-Windheuser \& W. Roebroeks (Eds.), Multidisciplinary studies of the Middle Palaeolithic Record from Neumark-Nord (Germany) (Vol. I, pp. 97-108). Halle: Landesamt für Denkmalpflege und Archäologie Sachsen-Anhalt.

Barsky, D., Vergès, J.-M., Sala, R., Menéndez, L., \& Toro-Moyano, I. (2015). Limestone percussion tools from the late Early Pleistocene sites of Barranco León and Fuente Nueva 3 (Orce, Spain). Phil. Trans. $R$. Soc. B, 370(1682), 20140352. https://doi.org/10.1098/rstb.2014.0352.

Blasco, R., Domínguez-Rodrigo, M., Arilla, M., Camarós, E., \& Rosell, J. (2014). Breaking bones to obtain marrow: a comparative study between percussion by batting bone on an anvil and hammerstone percussion. Archaeometry, 56(6), 1085-1104. https://doi.org/10.1111/arcm.12084.

Carvalho, S., Cunha, E., Sousa, C., \& Matsuzawa, T. (2008). Chaînes opératoires and resource-exploitation strategies in chimpanzee (Pan troglodytes) nut cracking. Journal of Human Evolution, 55(1), 148-163. https://doi.org/10.1016/j.jhevol.2008.02.005.

Conard, N. J., \& Adler, D. S. (1997). Lithic reduction and hominid behavior in the Middle Paleolithic of the Rhineland. Journal of Anthropological Research, 53(2), 147-175. https://doi.org/10.1086/jar.53.2.3631275.

de Beaune, S. A. (1993). Nonflint stone tools of the Early Upper Paleolithic. In H. Knecht, A. Pike Tay, \& R. White (Eds.), Before Lascaux: complex record of the early upper Paleolithic (pp. 163-191). Boca Raton: CRC Press Inc.

de Beaune, S. A. (2004). The invention of technology: prehistory and cognition. Current Anthropology, 45(2), 139-162. https://doi.org/10.1086/381045.

de la Torre, I., \& Hirata, S. (2015). Percussive technology in human evolution: an introduction to a comparative approach in fossil and living primates. Phil. Trans. R. Soc. B, 370(1682), 20140346. https://doi.org/10.1098/rstb.2014.0346.

de la Torre, I., \& Mora, R. (2010). A technological analysis of non-flaked stone tools in Olduvai Beds I \& II. Stressing the relevance of percussion activities in the African Lower Pleistocene. PALEO. Revue d'archéologie préhistorique, (Numéro spécial), 13-34.

de la Torre, I., Benito-Calvo, A., Arroyo, A., Zupancich, A., \& Proffitt, T. (2013). Experimental protocols for the study of battered stone anvils from Olduvai Gorge (Tanzania). Journal of Archaeological Science, 40(1), 313-332. https://doi.org/10.1016/j.jas.2012.08.007.

Deal, K. (2012). Fire effects on flaked stone, ground stone, and other stone artifacts. In K. Deal, L. DeBano, M. Elliot, C. Haecker, \& A. T. Jones (Eds.), Wildland fire in ecosystems effects of fire on cultural resources and archaeology (pp. 97-111). Lincoln: University of Nebraska.

Dubreuil, L. (2004). Long-term trends in Natufian subsistence: a use-wear analysis of ground stone tools. Journal of Archaeological Science, 31(11), 1613-1629. https://doi.org/10.1016/j.jas.2004.04.003.

Dubreuil, L., \& Savage, D. (2014). Ground stones: a synthesis of the use-wear approach. Journal of Archaeological Science, 48, 139-153. https://doi.org/10.1016/j.jas.2013.06.023.

Dubreuil, L., Savage, D., Delgado-Raack, S., Plisson, H., Stephenson, B., \& de la Torre, I. (2015). Current analytical frameworks for studies of use-wear on ground stone tools. In J. Marreiros, J. F. Gibaja Bao, \& N. F. Bicho (Eds.), Use-wear and residue analysis in archaeology (pp. 105-158). Berlin: Springer.

Fullagar, R., Hayes, E., Stephenson, B., Field, J., Matheson, C., Stern, N., \& Fitzsimmons, K. (2015). Evidence for Pleistocene seed grinding at Lake Mungo, South-Eastern Australia. Archaeology in Oceania, 50(S1), 3-19. https://doi.org/10.1002/arco.5053.

Fullagar, R., Stephenson, B., \& Hayes, E. (2017). Grinding grounds: function and distribution of grinding stones from an open site in the Pilbara, western Australia. Quaternary International, 427, 175-183. https://doi.org/10.1016/j.quaint.2015.11.141.

García-Moreno, A., Smith, G. M., Kindler, L., Pop, E., Roebroeks, W., Gaudzinski-Windheuser, S., \& Klinkenberg, V. (2016). Evaluating the incidence of hydrological processes during site formation through orientation analysis. A case study of the middle Palaeolithic Lakeland site of Neumark-Nord 2 (Germany). Journal of Archaeological Science: Reports, 6, 82-93. https://doi.org/10.1016/j. jasrep.2016.01.023.

Gaudzinski-Windheuser, S., Kindler, L., Pop, E., Roebroeks, W., \& Smith, G. (2014). The Eemian Interglacial lake-landscape at Neumark-Nord (Germany) and its potential for our knowledge of hominin subsistence strategies. Quaternary International, 331, 31-38. https://doi.org/10.1016/j.quaint.2013.07.023. 
Gilabert, X. R., Martínez-Moreno, J., \& Torcal, R. M. (2012). Pitted stone cobbles in the Mesolithic site of Font del Ros (Southeastern Pre-Pyrenees, Spain): some experimental remarks around a controversial tool type. Journal of Archaeological Science, 39(5), 1587-1598.

Goodall, J. (1964). Tool-using and aimed throwing in a community of free-living chimpanzees. Nature, 201, 1264-1266.

Goren-Inbar, N., Sharon, G., Melamed, Y., \& Kislev, M. (2002). Nuts, nut cracking, and pitted stones at Gesher Benot Ya'aqov, Israel. Proceedings of the National Academy of Sciences, 99(4), 2455-2460. https://doi.org/10.1073/pnas.032570499.

Goren-Inbar, N., Sharon, G., Alperson-Afil, N., \& Herzlinger, G. (2015). A new type of anvil in the Acheulian of Gesher Benot Ya'aqov, Israel. Phil. Trans. R. Soc. B, 370(1682), 20140353. https://doi.org/10.1098 /rstb.2014.0353.

Gumert, M. D., \& Malaivijitnond, S. (2013). Long-tailed macaques select mass of stone tools according to food type. Philosophical Transactions of the Royal Society B: Biological Sciences, 368(1630), 20120413. https://doi.org/10.1098/rstb.2012.0413.

Hamon, C. (2008). Functional analysis of stone grinding and polishing tools from the earliest Neolithic of north-western Europe. Journal of Archaeological Science, 35(6), 1502-1520. https://doi.org/10.1016/j. jas.2007.10.017.

Haslam, M., Luncz, L., Pascual-Garrido, A., Falótico, T., Malaivijitnond, S., \& Gumert, M. (2016). Archaeological excavation of wild macaque stone tools. Journal of Human Evolution, 96, 134-138. https://doi.org/10.1016/j.jhevol.2016.05.002.

Hayes, E. H., Cnuts, D., Lepers, C., \& Rots, V. (2017). Learning from blind tests: determining the function of experimental grinding stones through use-wear and residue analysis. Journal of Archaeological Science: Reports, 11, 245-260. https://doi.org/10.1016/j.jasrep.2016.12.001.

Hérisson, D., Locht, J.-L., Vallin, L., Antoine, P., Auguste, P., Limondin Lozouet, N., et al. (2015). Neandertal's presence during the Eemian Interglacial in North-Western Europe: a new site at Waziers (Northern France). PESHE, 4, 115.

Hesse, N., \& Kindler, L. (2014). Geologie und Genese der quartären Beckenfüllung Neumark-Nord 2 und deren Ausgrabung. In S. Gaudzinski-Windheuser \& W. Roebroeks (Eds.), Multidisciplinary studies of the Middle Palaeolithic record from Neumark-Nord (Germany) (Vol. I, pp. 13-38). Halle: Landesamt für Denkmalpflege und Archäologie Sachsen-Anhalt.

Jelinek, A. J. (2013). Neandertal lithic industries at La Quina. University of Arizona Press.

Jones, P. R. (1994). Results of experimental work in relation to the stone industries of Olduvai Gorge. Olduvai Gorge, 5, 1968-1971.

Kindler, L., Smith, G., \& Wagner, M. (2014). Introduction to the faunal analysis at Neumark-Nord 2. In S. Gaudzinski-Windheuser \& W. Roebroeks (Eds.), Multidisciplinary studies of the Middle Palaeolithic record from Neumark-Nord (Germany) (Vol. I, pp. 197-210). Halle: Landesamt für Denkmalpflege und Archäologie Sachsen-Anhalt.

Kuijper, W. (2014). Investigation of inorganic, botanical and zoological remains of an exposure of Last Interglacial (Eemian) sediments at Neumark - Nord 2 (Germany). In S. Gaudzinski-Windheuser \& W. Roebroeks (Eds.), Multidisciplinary studies of the Middle Palaeolithic record from Neumark-Nord (Germany) (Vol. I, pp. 79-96). Halle: Landesamt für Denkmalpflege und Archäologie Sachsen-Anhalt.

Langejans, G. H. (2012). Micro-residue analysis on Early Stone Age tools from Sterkfontein, South Africa: a methodological enquiry. The South African Archaeological Bulletin, 69(196), 200-213.

Leakey, M. D. (1966). A review of the Oldowan culture from Olduvai Gorge, Tanzania. Nature, 210, 462-466.

Luncz, L. V., Wittig, R. M., \& Boesch, C. (2015). Primate archaeology reveals cultural transmission in wild chimpanzees (Pan troglodytes verus). Phil. Trans. R. Soc. B, 370(1682), 20140348. https://doi.org/10.1098/rstb.2014.0348.

Mania, D. (1990). Stratigraphie, Ökologie und mittelpaläolithische Jagdbefunde des Interglazials von Neumark-Nord (Geiseltal). In D. Mania, M. Thomae, T. Litt, \& T. Weber (Eds.), Neumark-Gröbern: Beiträge zur Jagd des mittelpaläolithischen Menschen (pp. 9-113). Berlin: Deutscher Verlag der Wissenschaften.

Mania, D., \& Thomae, M. (2013). Zur Geologie und Stratigraphie der pleistozänen Becken von Neumark-Nord (Geiseltal). Veröffentlichungen des Landesamtes für Denkmalpflege und Archäologie Sachsen-Anhalt, 67.

Mathew, A., Wood, J., \& Oliver, C. (1991). Spots before your eyes: new comparison charts for visual percentage estimation in archaeological materials. Recent Developments in Ceramic Petrology, 211-263.

Mercader, J., Panger, M., \& Boesch, C. (2002). Excavation of a chimpanzee stone tool site in the African rainforest. Science, 296(5572), 1452-1455. https://doi.org/10.1126/science.1070268. 
Mercader, J., Barton, H., Gillespie, J., Harris, J., Kuhn, S., Tyler, R., \& Boesch, C. (2007). 4,300-year-old chimpanzee sites and the origins of percussive stone technology. Proceedings of the National Academy of Sciences, 104(9), 3043-3048. https://doi.org/10.1073/pnas.0607909104.

Mora, R., \& de la Torre, I. (2005). Percussion tools in Olduvai Beds I and II (Tanzania): implications for early human activities. Journal of Anthropological Archaeology, 24(2), 179-192. https://doi.org/10.1016/j. jaa.2004.12.001.

Mücher, H. J. (2014). Neumark-Nord 2, a shallow Eemian pool in northern Central Germany. A micromorphological study of its infill. In S. Gaudzinski \& W. Roebroeks (Eds.), Multidisciplinary studies of the Middle Palaeolithic record from Neumark-Nord (Germany) (Vol. I, pp. 39-46). Halle: Landesamt für Denkmalpflege und Archäologie Sachsen-Anhalt.

Nakazawa, Y., Straus, L. G., González-Morales, M. R., Solana, D. C., \& Saiz, J. C. (2009). On stone-boiling technology in the Upper Paleolithic: behavioral implications from an Early Magdalenian hearth in El Mirón Cave, Cantabria, Spain. Journal of Archaeological Science, 36(3), 684-693. https://doi.org/10.1016/j.jas.2008.10.015.

Pop, E. (2014). Analysis of the Neumark-Nord 2/2 lithic Assemblage: results and interpretations. In S. Gaudzinski-Windheuser \& W. Roebroeks (Eds.), Multidisciplinary studies of the Middle Palaeolithic record from Neumark-Nord (Germany) (Vol. I, pp. 143-196). Halle: Landesamt für Denkmalpflege und Archäologie Sachsen-Anhalt.

Pop, E. (2015). Neandertal adaptations to Interglacial conditions - a case study from the Eemian site Neumark-Nord 2 (Germany). (Doctoral dissertation) Leiden University.

Pop, E., \& Bakels, C. (2015). Semi-open environmental conditions during phases of hominin occupation at the Eemian interglacial (OIS5e) basin site Neumark-Nord 2. Quaternary Science Reviews, 117, 72-81. https://doi.org/10.1016/j.quascirev.2015.03.020.

Pop, E., Bakels, C., Kuijper, W., Mücher, H. J., \& van Dijk, M. (2015). The dynamics of small postglacial lake basins and the structure of their archaeological record: a case study of the Middle Palaeolithic site Neumark-Nord 2, Germany. Geoarchaeology, 30(5). https://doi.org/10.1002/gea.21526.

Pop, E., Kuijper, W., van Hees, E., Smith, G., García-Moreno, A., Kindler, L., et al. (2016). Fires at NeumarkNord 2, Germany: an analysis of fire proxies from a Last Interglacial Middle Palaeolithic basin site. Journal of Field Archaeology, 41(5), 603-617. https://doi.org/10.1080/00934690.2016.1208518.

Proffitt, T., Luncz, L. V., Falótico, T., Ottoni, E. B., de la Torre, I., \& Haslam, M. (2016). Wild monkeys flake stone tools. Nature, 539(7627), 85-88. https://doi.org/10.1038/nature20112.

Richter, D., \& Krbetschek, M. (2014). Preliminary luminescence dating results for two middle Palaeolithic occupations at Neumark-Nord 2. In S. Gaudzinski-Windheuser \& W. Roebroeks (Eds.), Multidisciplinary studies of the Middle Palaeolithic record from Neumark-Nord (Germany) (Vol. I, pp. 131-136). Halle: Landesamt für Denkmalpflege und Archäologie Sachsen-Anhalt.

Roebroeks, W. (1988). From find scatters to early hominid behaviour. Analecta Praehistoria Leidensia, 21, 1-196.

Roffman, I., Savage-Rumbaugh, S., Rubert-Pugh, E., Ronen, A., \& Nevo, E. (2012). Stone tool production and utilization by bonobo-chimpanzees (Pan paniscus). Proceedings of the National Academy of Sciences, 109(36), 14500-14503. https://doi.org/10.1073/pnas.1212855109.

Rots, V. (2010). Prehension and hafting traces on flint tools: a methodology. Universitaire Pers Leuven.

Roussel, M., Bourguignon, L., \& Soressi, M. (2009). Identification par l'expérimentation de la percussion au percuteur de calcaire au Paléolithique moyen: le cas du façonnage des racloirs bifaciaux Quina de Chez Pinaud (Jonzac, Charente-Maritime). Bulletin de la Société préhistorique française, 106(2), 219-238. https://doi.org/10.2307/23240605.

Rowan, Y. M., \& Ebeling, J. R. (2008). Introduction: the potential of ground stone studies. In Y. M. Rowan \& J. R. Ebeling (Eds.), New approaches to old stones: recent studies of ground stone artifacts (pp. 1-15). London: Equinox.

Schick, K. D., \& Toth, N. (1994). Early Stone Age technology in Africa: a review and case study into the nature and function of spheroids and subspheroids. In R. S. Corruccini \& R. L. Ciochon (Eds.), Integrative paths to the past. Paleoanthropological advances in honor of F. Clark Howell (pp. 429449). Upper Saddle River: Prentice Hall.

Sier, M. J., Roebroeks, W., Bakels, C. C., Dekkers, M. J., Brühl, E. B., De Loecker, D., et al. (2011). Direct terrestrial-marine correlation demonstrates surprisingly late onset of the last interglacial in central Europe. Quaternary Research, 75(1), 213-218. https://doi.org/10.1016/j.yqres.2010.11.003.

Speleers, B. (2000). The relevance of the Eemian for the study of the Palaeolithic occupation of Europe. Geologie en Mijnbouw, 79, 283-292. https://doi.org/10.1017/S0016774600021764.

Strahl, J., Krbetschek, M. R., Luckert, J., Machalett, B., Meng, S., Oches, E. A., et al. (2010). Geologie, Paläontologie und Geochronologie des Eem-Beckens Neumark-Nord 2 und Vergleich mit dem Becken 
Neumark-Nord 1 (Geiseltal, Sachsen-Anhalt). Quaternary Science Journal, 59, 120-167. https://doi. org/10.23689/fidgeo-1158.

Thieme, H. (1975). Schleif-oder Reibplatten des fundplatzes Rheindahlen-Ostecke, Ziegeleigrube Dressen, Stadtkr. Monchengladbach in Festschrift Hermann Schwabedissen. Teil I: Beiträge zum Paläolithikum und Neolithikum. Kolner Jahrbuch für Vor-und Frühgeschichte Berlin, 15, 24-30.

Thieme, H., Veil, S., \& Meyer, W. (1985). Neue Untersuchungen zum eemzeitlichen Elefanten-Jagdplatz Lehringen, Ldkr. Verden. Die Kunde, 36, 11-85.

Thomae, M. (1990). Geologischer Aufbau und Lagerungsverhältnisse des Quartärprofils von Neumark-Nord. In D. Mania, M. Thomae, T. Litt, \& T. Weber (Eds.), Neumark-Gröbern: Beiträge zur Jagd des mittelpaläolithischen Menschen (pp. 113-143). Berlin: Deutscher Verlag der Wissenschaften.

Toepfer, V. (1958). Steingeräte und Palökologie der mittelpaläolithischen Fundstelle Rabutz. Jahresschrift für Mitteldeutsche Vorgeschichte, 41(42), 140-177.

Turq, A., Roebroeks, W., Bourguignon, L., \& Faivre, J.-P. (2013). The fragmented character of Middle Palaeolithic stone tool technology. Journal of Human Evolution, 65(5), 641-655. https://doi.org/10.1016 /j.jhevol.2013.07.014.

Van Gijn, A. L. (1989). The wear and tear of flint: principles of functional analysis applied to Dutch Neolithic assemblages. Analecta Praehistorica Leidensia, 22, 1-181.

Van Gijn, A. L. (2009). Flint in focus: lithic biographies in the Neolithic and Bronze Age. Leiden: Sidestone Press.

Van Gijn, A. L. (2014). Science and interpretation in microwear studies. Journal of Archaeological Science, 48, 166-169. https://doi.org/10.1016/j.jas.2013.10.024.

Vaquero, M., \& Romagnoli, F. (2017). Searching for lazy people: the significance of expedient behavior in the interpretation of Paleolithic assemblages. Journal of Archaeological Method and Theory, 1-34. https://doi.org/10.1007/s10816-017-9339-x.

Verbaas, A., \& Van Gijn, A. L. (2008). Querns and other hard stone tools from Geleen-Janskamperveld. Analecta Praehistorica Leidensia, 39, 191-204.

Veselsky, A. P. (2008). Kabazi V, Sub-Unit III/1: The Starosele Facie of Micoquian. In V. Chabai, J. Richter, \& T. Uthmeier (Eds.), Kabazi V: Interstratification of Micoquian \& Levallois-Mousterian Camp Sites (Vol. 2, pp. 129-179). Simferopol-Cologne: Shlyakh.

Wansa, S., \& Radzinski, K. (2004). Erläuterungen zur Geologischen Karte von Sachsen-Anhalt 1:25000, Blatt 4636 Mücheln (Geiseltal).

Wansa, S., Strahl, J., \& Rappsilber, I. (2014). Korrelation von Schichtenfolgen aus den Eembecken NeumarkNord 1 und 2 (Geiseltal). In S. Gaudzinski-Windheuser, W. Roebroeks, \& H. Meller (Eds.), Multidisciplinary studies of the Middle Palaeolithic record from Neumark-Nord (Germany) (Vol. I, pp. 47-68). Halle: Landesamt für Denkmalpflege und Archäologie Sachsen-Anhalt.

Wenthworth, C. K. (1922). The Wenthworth scale of grain size for sediments. Journal of Geology, $30,381$.

Whiten, A., Schick, K., \& Toth, N. (2009). The evolution and cultural transmission of percussive technology: integrating evidence from palaeoanthropology and primatology. Journal of Human Evolution, 57(4), 420435. https://doi.org/10.1016/j.jhevol.2008.12.010. 